\title{
Prevalence of Malaria and Associated Factors among Patients Attending at Hallaba Health Center, Southern Ethiopia
}

\author{
Girum Tefera \\ Tehran University of medical sciences, Department of Medical Biotechnology, Iran \\ *Corresponding Author: tgirumt@gmail.com
}

Copyright (C) 2014 Horizon Research Publishing All rights reserved.

\begin{abstract}
Back ground: Malaria is usually an important hazard in order to open health and economic progress inside the African continent. Throughout sub-Saharan the African continents, $90 \%$ of all demise largely below 5 youngsters tend to be due to malaria. Yearly you can find in relation to 270-480 million circumstances associated with malaria leading to in relation to one million demise, largely inside The African continent as well as especially within 5 youngsters. Almost all of the full division of Ethiopia is actually malarious, doing malaria the best open health problem inside Ethiopia. The purpose of this particular review seemed to be to look into your frequency as well as associated factors among patients attending at Hallaba health center based on thick and thin blood film examination. Thus, this research was launched to determine the prevalence of malaria and associated factors among patients who attended at Hallaba health center. Methods: Health center based cross sectional study was conducted from April 19 to June 21, 2009 at Hallaba health center on a total of 204 individuals who were selected conveniently. Structured questionnaire was used to obtain socio-demographic and other data. Then the data were entered and analyzed by using SPSS software. Statistical tables and graphs were used to present the result. Chi-square tests and OR $(95 \% \mathrm{CI})$ were used to test the association. Results: The analyses showed that the highest prevalence of malaria was found between age group of 0-19 year. There was association between age group and prevalence of malaria $(\mathrm{X} 2=77.07, \mathrm{P}<0.005)$ and also there was association between prevalence of malaria and sign and symptom like fever $(\mathrm{OR}=11.84 \%, 95 \% \mathrm{CI}, 4.62-30.27$, $\mathrm{P}<0.005)$. Vomiting $(\mathrm{OR}=8.29, \quad 95 \%$ CI $3.39-20.49$, $\mathrm{P}<0.005)$. Chills $(\mathrm{OR}=8.76,95 \%$ CI $3.71-20.70, \mathrm{P}<0.005)$ Joint and back pain $(\mathrm{OR}=3.85,95 \% \mathrm{CI} 1.26-11.94, \mathrm{P}<0.005)$, headache $(\mathrm{OR}=75.17,95 \%$ CI 21.12-270.43, $\mathrm{P}<0.005)$. Conclusion: Those with inadequate socio-economic conditions are really linked to malaria contamination. On the result it can be concluded that most of the respondents were infected with Plasmodium vivax. The respondents' knowledge or having information about malaria has no association with the prevalence of malaria. Age, altitude,
\end{abstract}

rainfall and socio-economic factors contribute to high prevalence of malaria at Hallaba health Center. This kind of facts is vital to style increased strategic involvement with the lessening connected with malaria pandemic in Halaba town. Generally, from the result of this study it can concluded that the prevalence of Plasmodium vivax and Plasmodium falciparum is different from the national figure.

Keywords Age, Malaria, Prevalence, Plasmodium Vivax, Plasmodium Falciparum, Altitude, Socio Economic Factor

\section{Introduction}

Malaria is surely an infectious illness fed by simply women anopheles mosquitoes. It truly is a result of protozoan parasite from the genus plasmodium which in turn infects people. Malaria is often a key risk in order to general public health and fiscal improvement throughout Photography equipment. Throughout sub-Saharan Photography equipment $90 \%$ of all demise, mainly under 5 children are because of malaria (1). Yearly, you can find concerning 270-480 million cases connected with malaria causing concerning one particular million demise, primarily throughout Photography equipment and also specially inside of 5 children. These kinds of fiscal damage because of malaria throughout Photography equipment throughout 1985 had been approximated being US\$ 800 million and also by simply 2000 the idea increased in order to US\$ 12 billion dollars (2). Tropical Africa is generally epidemic to Plasmodium falciparum due to the absence of $\mathrm{Fy}^{\mathrm{a}} / \mathrm{Fy}^{\mathrm{b}}$ Duffy antigens. It is however reported to be allopatric to Plasmodium ovalae which is epidemic in the western part of the continent (3). Among the four plasmodium species known to cause malaria in Ethiopia, the two epidemiologically important species are Plasmodium falciparum and Plasmodium vivax comprising $60 \%$ and $40 \%$ respectively (3). Plasmodium falciparum is the cause of 
severe and complicated malaria which cause fatality rate of about $10 \%$ in hospitalized adults and up to $33 \%$ in children $<12$ years old (3) Latest appraisal suggested of which no less than one in order to several million children perish because of malaria annually throughout Photography equipment on your own. Work in order to get rid of malaria have was unable and also parasite amount of resistance towards the in most cases utilized and also inexpensive anti-malarial medications can be developing swiftly. Insecticide amount of resistance vector can be an evolving problem. Some sort of malaria vaccine can be the subject of a lot study but it is assessment can be imperfect and also whole deployment is always a new far-away target. (4, 5, 6, 7). Even with mankind's longstanding battle to command mosquito populations, the globe Health and fitness Business approximated that many season malaria will cause 3 hundred in order to 500 million microbe infections and also around 1 million demise annually. $(4,5,6,7)$

Malaria is perhaps even more complicated in order to fight as compared to HIV or even tuberculosis because of its several distinct life-cycle development and genetic intricacy, allowing Plasmodium in order to adjust swiftly in order to medications and your immune system bodies attempts in order to provide the idea inadequate. Using huge amounts of unwanted organisms becoming more common in one man host, Plasmodium variety are ready in order to resist immunologic and also chemotherapeutic violence. With the aid of mosquito vectors, an individual afflicted individual could transfer in order to many different people within just weeks, a lot outstripping the infectiousness connected with HIV or even tuberculosis. Four species of plasmodium infects human beings. These are Plasmodium vivax, Plasmodium falciparum, Plasmodium ovalae and plasmodium malarae. (11)

\section{Material and Method}

\subsection{Information in the Examine Place}

Hallaba exclusive section is situated in the west of Hawassa town along Shashemene road at a distance of $85 \mathrm{~km}$ from Hawassa and $310 \mathrm{~km}$ from Addis-Ababa. It has an astronomical location of $7^{0} 17^{\prime} \mathrm{N}$ latitude and $38^{\circ} 06^{\prime} \mathrm{E}$ longitude. Hallaba town is found $1554 \mathrm{~m}$ to $2149 \mathrm{~m}$ above sea level. But most part of it found at about $1800 \mathrm{~m}$ above sea level. It has dry climatic condition with annual rainfall of $857 \mathrm{~mm}$ and its annual temperature is $17^{\circ} \mathrm{C}-20^{\circ} \mathrm{C}$. The total population of Hallaba district is 259,810 among these 129893 are males and129917 are females.

\subsection{Study Design}

This study was conducted at Hallaba health center. Health center primarily based cross-sectional review was performed to look for the epidemic regarding malaria along with related variables at Hallaba health center.

\subsection{Source of Population and Study Population}

The source of population was the population of Hallaba town and surrounding. The study population was the population who requested for blood film examination.

\subsection{Sample Size}

The sample size was determined by using the general formula as follows:

$$
\mathrm{n}=\frac{\left(\mathrm{z}^{2} \mathrm{I}-\alpha / 2 \times \mathrm{p}(1-\mathrm{p})\right.}{\mathrm{d}^{2}}
$$

Where, $\mathrm{ZI}-\alpha / 2$ is the relativity factor for a given level (for $95 \%$ CI Level $\mathrm{Z}=1.96$ ), $\mathrm{P}=$ prevalence of malaria in Ethiopia $=14 \%(0.14) . \mathrm{d}=$ is margin of error to be tolerated, $\mathrm{d}=0.05$.

\subsection{Sampling Technique}

Conveniently sampling technique was used to collect the study units. Conveniently blood sample was collected to prepare thick and thin blood film smears. This is more convenient than taking a random blood sample of people who live in Hallaba town and surrounding. Moreover, structured questionnaire was used to collect relevant data.

\subsection{Sample Collection Method and Preparation}

Blood sample was collected to prepare thick and thin blood film smears. Then thin smear was fixed by methanol and stain both thin and thick blood film smears in giemsa staining solution. Finally the dried blood films were examined under microscope with $100 x$ oil immersion.

\subsection{Method of Data Collection}

Structured questionnaire was used to collect the necessary information. The interview included the following information: age, income, knowledge about malaria, sex, health service facility, socio economic status and other related information. The study unit blood film examination result was recorded.

\subsection{Sample Collection}

Capillary blood was collected aseptically using a sterile blood lancet. Each slide was labeled by using lead pencil followed by preparing both thick and thin blood film smears and stain it in giemsa staining solution. Finally microscopic examination and malaria species identification was done. Then the data were entered and analyzed by using SPSS software. Statistical tables and graphs were used to present result. Chi-square tests and OR (95\% CI) were used to test the association.

\section{Results}

From 204 study population (82.84\%) 169 were found positive for plasmodium species, of which (70.41\%) 119 were due to Plasmodium vivax, (23.08\%) 39 were 
Plasmodium falciparum and (6.51\%) 11 were mixed infection. The highest prevalence malaria was found between age group of 0-19 year. There was association between age group and prevalence of malaria $\left(\mathrm{X}^{2}=77.07\right.$, $\mathrm{P}<0.005)$ and also there was association between prevalence of malaria and sign and symptom like fever $(\mathrm{OR}=11.84 \%$, 95\%CI,4.62-30.27, $\mathrm{P}<0.005)$, vomiting $\quad(\mathrm{OR}=8.29,95 \% \quad \mathrm{CI}$ 3.39-20.49, $\mathrm{P}<0.005)$. Chills $(\mathrm{OR}=8.76,95 \% \mathrm{CI} \quad 3.71-20.70$, $\mathrm{P}<0.005)$ Joint and back pain $(\mathrm{OR}=3.85,95 \%$ CI 1.26-11.94, $\mathrm{P}<0.005)$, head ache $(\mathrm{OR}=75.17$, 95\% CI 21.12-270.43, $\mathrm{P}<0.005)$.

\section{Distribution and types of plasmodium species}

A total of 204 samples were taken and blood films were examined for investigation of plasmodium species. As table -2- shows 204 individuals examined for plasmodium species (82.84\%) 169 were found positive for malaria parasites. Out of these positive (70.41\%) 119 were positive for Plasmodium vivax. Plasmodium falciparum accounts
(23.08\%) 39 from the total positive cases (6.51\%) 11 of them had mixed infection (figure 1).

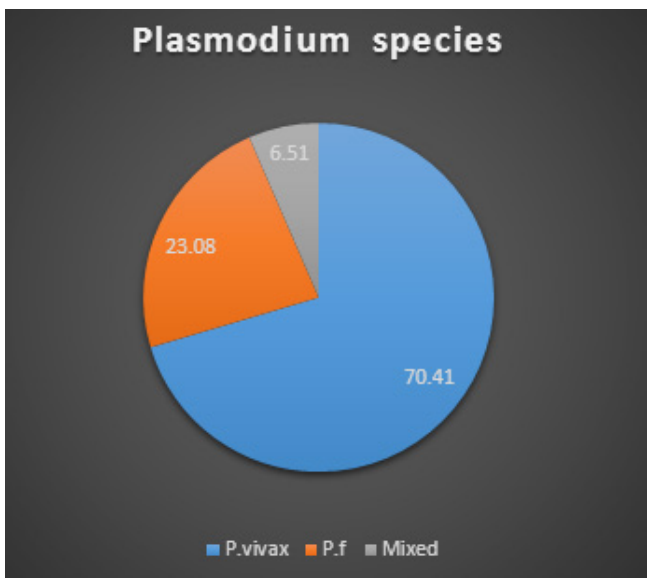

Figure 1. Prevalence of plasmodium species among respondents at Hallaba health center.

Table 1. Distribution of plasmodium species by sex of the study subject at Hallaba health center.

\begin{tabular}{|c|c|c|c|c|c|c|c|}
\hline \multirow{2}{*}{ Sex } & \multicolumn{4}{|c|}{ Plasmodium species } & \multirow{2}{*}{$\begin{array}{c}\text { Total } \\
\text { No. } \%\end{array}$} & \multirow{2}{*}{$\mathrm{X}^{2}$} & \multirow{2}{*}{$\mathrm{Df}$} \\
\hline & $\begin{array}{l}\text { P.vivax } \\
\%\end{array}$ & $\begin{array}{c}\text { P.falciparum } \\
\%\end{array}$ & $\begin{array}{c}\text { Mixed } \\
\%\end{array}$ & $\begin{array}{c}\text { Negative } \\
\%\end{array}$ & & & \\
\hline Male & $56(47.06$ & $12(30.77)$ & $4(36.36)$ & $21(60)$ & $93(45.6)$ & 6.85 & 3 \\
\hline Female & $63(52.94)$ & $27(69.23)$ & $7(63.64)$ & $14(40)$ & $11(54.4)$ & $\mathrm{p}>0.005$ & \\
\hline Total & $119(100)$ & $39(100)$ & $11(100)$ & $35(100)$ & $204(100)$ & & \\
\hline
\end{tabular}

Table 2. Distribution of plasmodium species with age group of the study subject at Hallaba heath center.

\begin{tabular}{|c|c|c|c|c|c|c|c|}
\hline \multirow{2}{*}{ Age group } & \multicolumn{4}{|c|}{ Plasmodium species } & \multirow{2}{*}{ Total } & \multirow{2}{*}{$X^{2}$} & \multirow{2}{*}{ Df } \\
\hline & P.vivax & p.falciparum & Mixed & Negative & & & \\
\hline $0-4$ & 26 & 7 & 1 & - & 34 & \multirow{8}{*}{$X^{2}=77.07$} & \multirow{8}{*}{33} \\
\hline $5-9$ & 22 & 7 & 4 & - & 33 & & \\
\hline $10-14$ & 16 & 5 & 3 & - & 24 & & \\
\hline $15-19$ & 14 & 5 & - & - & 19 & & \\
\hline $20-24$ & 3 & 1 & - & 3 & 7 & & \\
\hline $25-29$ & 1 & 3 & - & 18 & 22 & & \\
\hline $30-34$ & 3 & 4 & - & 8 & 15 & & \\
\hline $35-39$ & 2 & 3 & - & 6 & 11 & & \\
\hline $40-44$ & 9 & 1 & - & - & 10 & \multirow{5}{*}{$\mathrm{P}<0.005$} & \\
\hline $45-49$ & 6 & 2 & 1 & - & 9 & & \\
\hline $50-54$ & 8 & - & 1 & - & 9 & & \\
\hline$>55$ & 9 & 1 & 1 & - & 11 & & \\
\hline Total & 119 & 39 & 11 & 35 & 204 & & \\
\hline
\end{tabular}




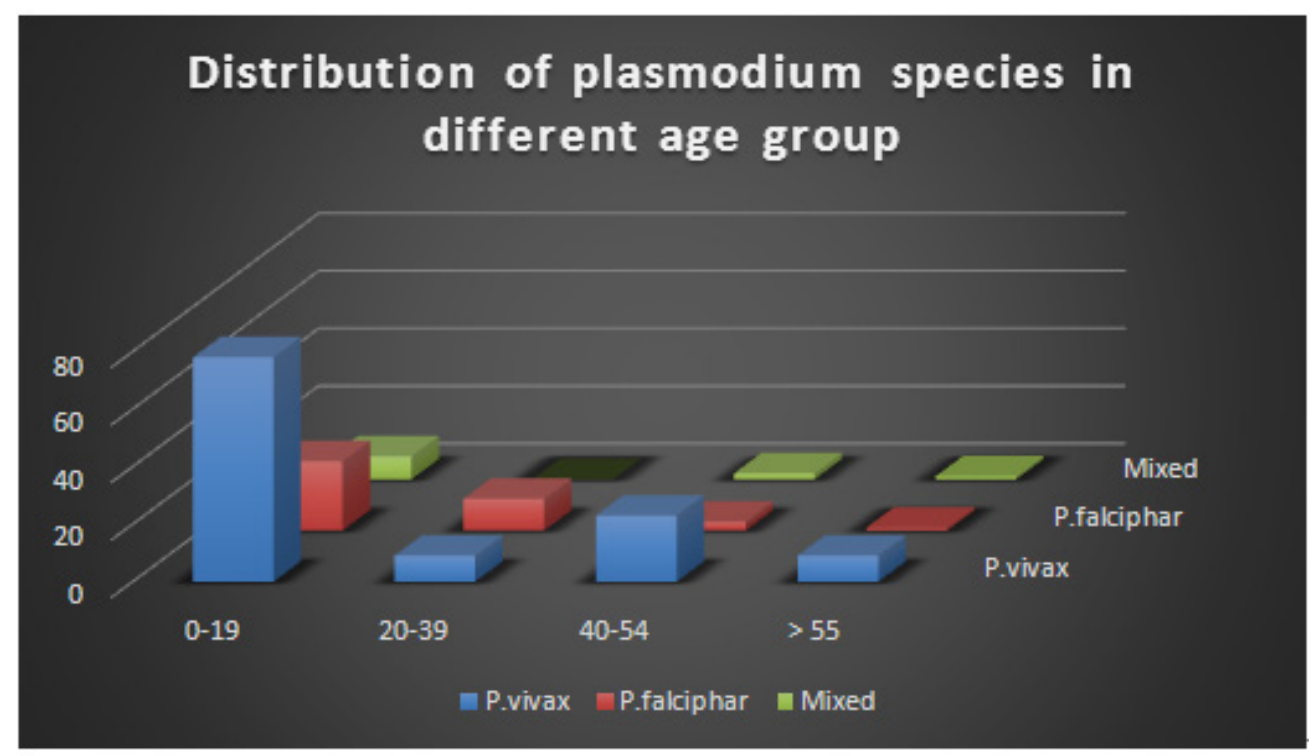

Figure 2. Distribution of plasmodium species in different age groups at Hallaba health center.

\section{Distribution of plasmodium species by sex}

As indicated in table-1, the distribution of plasmodium species by sex, out of 169 malaria positives the majority $(57.40 \%) 97$ were females and $(42.6 \%) 72$ were males. Out of all males examined $(77.77 \%) 56$ were positive for Plasmodium vivax and (16.67\%) 12 were positive for Plasmodium falciparum and the rest (5.56\%) 4 were mixed infection. While in the case of females( $64.95 \%) 63$ were positive for Plasmodium vivax and( 27.84\%) 27 were positive for Plasmodium falciparum and ( $7.22 \%) 7$ were mixed infection. For the rest, $(60.0 \%) 21$ of males and $(40.0 \%) 14$ of females no malaria parasite was seen during the examination of their blood film. (Table-1)

The highest prevalence of malaria was seen in the age group of $0-19$ years, which is $100 \%$ of the total examined 69 individuals, $40-54$ years which is $100 \%$ of the total of examined 15 individuals and $>55$ years which is also $100 \%$ of the total of examined 5 individual. The least positivity was seen in the age group of $25-29$ years which is $56 \%$ of the total of examined 41 individuals. In the majority of the age group the dominant plasmodium species is Plasmodium vivax (Table 2).

\section{Discussion}

In this study, from the total of 169 positive cases (70.41\%) 119 were Plasmodium vivax and (23.08\%) 39 were Plasmodium falciparum and remaining, (6.51\%) 11 were mixed infection, this result is quite different from the national prevalence of Plasmodium falciparum and Plasmodium vivax which is $60 \%$ and $40 \%$ respectively. This study contradict with the study conducted in Jimma zone at Assendabo health center, which reported prevalence of Plasmodium vivax (45.7\%)48 and Plasmodium falciparum (54.3\%) 57 from total of 365 study population (10). The other is the one which was conducted in five zone of Eritrea in 13,279 individuals in 1999 were Plasmodium falciparum accounts $90.5 \%$ and Plasmodium vivax accounts $9.5 \%$ of positive cases which are 285. This may be due to the difference in the study area, study period, sample size as well as study population in which those studies focused on (8).However this study partly in line with the study finding reported from southern Ethiopia health and health related indicator in 1992 in which out of 61,079 positive cases $47.2 \%$ were Plasmodium falciparum and $50.9 \%$ were Plasmodium vivax indicating the lower number of Plasmodium falciparum in the region. The other study performed in Assendabo health center showed that $75 \%$ were positive for Plasmodium vivax and $32.5 \%$ were positive for Plasmodium falciparum which also parts confirmed with findings of this study (10). In addition to these this study is also related with the study conducted at Aleta wondo in 2007 on 185 study subjects which indicates that $(66 \%) 68$ were Plasmodium vivax and (34\%)35 Plasmodium falciparum infection from (55.7\%) 103 positive cases (12). These two results indicate the lower number of Plasmodium falciparum in the region. Moreover, the result of this study agree with the study conducted in Akaki in 1995 on 2136 sample were (5.7\%) 78 positive cases found mainly account to Plasmodium vivax $(69 \%) 54$ and (31\%) 24 were due to plasmodium falciparum (9). This may be due to the relapsing characteristics of Plasmodium vivax at the time of cold season (9). The deviation between the finding of this study and the national figure of epidemic regarding Plasmodium vivax along with Plasmodium falciparum is because of your relapsing conduct regarding Plasmodium vivax. As outlined by, the information obtained from rural development health office of Hallaba, preventive and curative actions were taken when there is Plasmodium falciparum epidemic. But there had never been vector control action taken during plasmodium vivax infection. The highest prevalence of 
malaria found in age groups $0-19$, the reason behind this increased prevalence of malaria in this specific age group is attributed to relatively low level of immunity and self-protection from vector attack and also may be due to improper usage of bed net.According to 3 years $(2006,2007$ and 2008) annual reports obtained from rural development health office of Hallaba special district, there is high prevalence of Plasmodium vivax. The result of this study also revealed high prevalence of Plasmodium vivax.

\section{Conclusions}

From the result it can be concluded that most of the respondents infected with Plasmodium vivax. In hallaba, southern Ethiopia Plasmodium vivax infection is highly prevalent than Plasmodium falciparum. The study revealed that there is association between age group and prevalence of malaria. Highest prevalence of malaria was seen for 0-19, 40-54 and $>55$ age groups. The respondents' knowledge about malaria has no association with the prevalence of malaria as well as owners of bed net.

The sign and symptom like fever, vomiting, chills, joint and back pain and headache are associated with the prevalence of malaria. Generally, from the result of this study it can be concluded that the prevalence of Plasmodium vivax and Plasmodium falciparum is different from the national figure.

\section{Ethics Agreement}

Each and every interviewee had been educated around the ambitions with the questionnaire along with their permission had been attained. Personal malaria standing outcomes were being found along with told just about every participator. The analysis acquired honorable agreement coming from Hawassa University along with the head office Hallaba area administration.

\section{REFERENCES}

[1] Federal Ministry of health (FMH): National five-year strategic plan for malaria Prevention and control in Ethiopia 2006 - 2010. Addis Ababa, Ethiopia: Federal democratic Republic of Ethiopia, Ministry of Health; 2006.

[2] World health organization framework for development, implementing and updating national anti-malaria treatment policy. World health organization office for Africa, 2004.

[3] Federal Ministry of Health (FMH): Malaria: Diagnosis and Treatment guide line for Health Workers in Ethiopia. Addis Ababa, Ethiopia: Federal democratic Republic of Ethiopia, Ministry of Health; 2004.

[4] Collinsk, Hall L and J.S.Faucil A .National institution of allergy and infectious disease; National institution of health. April 21, 2006, P, 17

[5] The burden of malaria of Africa .Africa malaria report 2003; p, $1,2-6$

[6] Getenet Mitike .Module on malaria. Gonder College of medical sciences Ethiopia.2005; p, 16-18

[7] Hailemariam A. Malaria prevention and control in Ethiopia: Malaria consortium, Ethiopia, 2007; p, 127

[8] Prevalence and distribution of malaria parasites in Eritrea, 1999; p, 8-9, 24

[9] Woyessa A.Gebre michaelT. Ali A. Aninding eneousis malaria transmission in the out strike of Addis-Ababa,Akaki town and its environment: Ethiopia journal of health development.2004;18910:61-66

[10] Ghebreyesus T, Haile M, Witten K, Getachew A, Yohannes M, Lindsay S: House hold risk factors for malaria among children in the Ethiopian highlands. Trans R Soc Trop Med Hyg 2000, 94:17-21.

[11] Adhanom TDW, Witten HK, Getachew A, Seboxa T: Malaria. In the Epidemiology and Ecology of Health and Disease in Ethiopia 1st edition. Edited by Berhane Y Hailemariam D, Kloos H. Ababa Addis, Ethiopia: Shama PLC; 2006:556-576

[12] Milikit D. Worede A,molargiT,Aboye G,GebrehiwotT. Prevalence of malaria among patients attending in aleta wondo health center.Southern Ethiopia,2007;p,13-26 